\title{
Neurogenesis and gliogenesis modulation in cerebral ischemia by CDK5 RNAi-based therapy
}

Juan Ignacio Muñoz-Manco, Johanna Andrea Gutiérrez-Vargas, Gloria Patricia Cardona-Gómez

Grupo de Neurociencias de Antioquia, Área de Neurobiología Celular y Molecular, Facultad de Medicina, Universidad de Antioquia, Medellín, Colombia

Introduction: Cerebral ischemia is the third cause of death risk in Colombia and the first cause of physical disability worldwide. Different studies on the silencing of the cyclin-dependent kinase 5 (CDK5) have shown that reducing its activity is beneficial in ischemic contexts. However, its effect on neural cell production after cerebral ischemia has not been well studied yet.

Objective: To evaluate CDK5 silencing on the production of neurons and astrocytes after a focal cerebral ischemia in rats.

Materials and methods: We used 40 eight-week-old male Wistar rats. Both sham and ischemia groups were transduced at CA1 hippocampal region with an adeno-associated viral vector using a noninterfering (shSCRmiR) and an interfering sequence for CDK5 (shCDK5miR). We injected $50 \mathrm{mg} / \mathrm{kg}$ of bromodeoxyuridine intraperitoneally from hour 24 to day 7 post-ischemia. We assessed the neurological abilities during the next 15 days and we measured the immunoreactivity of bromodeoxyuridine (BrdU), doublecortin (DCX), NeuN, and glial fibrillary acid protein (GFAP) from day 15 to day 30 post-ischemia. Results: Our findings showed that CDK5miR-treated ischemic animals improved their neurological score and presented increased BrdU+ ${ }^{+}$cells 15 days after ischemia, which correlated with higher DCX and lower GFAP fluorescence intensities, and, although mature neurons populations did not change, GFAP immunoreactivity was still significantly reduced at 30 days post-ischemia in comparison with untreated ischemic groups.

Conclusion: CDK5miR therapy generated the neurological recovery of ischemic rats associated with the induction of immature neurons proliferation and the reduction of GFAP reactivity at short and longterm post-ischemia.

Key words: Brain ischemia; neurogenesis; cyclin-dependent kinase 5.

doi: https://doi.org/10.7705/biomedica.v38i4.3800

\section{Modulación de la neurogénesis y la gliogénesis en la isquemia cerebral mediante una terapia basada en la interferencia de CDK5}

Introducción. La isquemia cerebral es la tercera causa de riesgo de muerte en Colombia y la primera causa de discapacidad física en el mundo. En diversos estudios en los que se silenció la cinasa 5 dependiente de la ciclina (CDK5) se ha demostrado que la reducción de su actividad es beneficiosa frente a la isquemia. Sin embargo, su efecto sobre la neurogénesis después de la isquemia no se ha dilucidado suficientemente.

Objetivo. Evaluar el silenciamiento de la CDK5 en la neurogénesis y la gliogénesis después de la isquemia cerebral focal en ratas.

Materiales y métodos. Se usaron 40 machos de rata Wistar de ocho semanas de edad. Los grupos de control y los isquémicos sometidos a transducción en la región del hipocampo CA1, se inyectaron intraperitonealmente por estereotaxia con $50 \mathrm{mg} / \mathrm{kg}$ de bromodesoxiuridina (BrdU) a partir de las 24 horas y hasta el día 7 después de la isquemia, con un vector viral asociado a adenovirus usando una secuencia no interferente (SCRmiR) y una interferente (CDK5miR). Se evaluó la capacidad neurológica durante los quince días siguientes y se detectó la capacidad de inmunorreacción para la BrdU, la proteína doblecortina (DCX), los núcleos neuronales (NeuN), y la proteína fibrilar acídica de la glía (Glial Fibrillary Acidic Protein, GFAP) a los 15 y 30 días de la isquemia.

Resultados. Los animales isquémicos tratados con CDK5miR mejoraron su puntuación neurológica y presentaron un incremento de la $\mathrm{BrdU}^{+}$a los 15 días de la isquemia, lo cual se correlacionó con

\footnotetext{
Author's contributions:

Juan Ignacio Muñoz-Manco: experiments and writing of the manuscript

Johanna Andrea Gutiérrez-Vargas: support for experiments and critical revision of the manuscript

Gloria Patricia Cardona-Gómez: critical revision of the manuscript intellectual content

All authors contributed to the study concept and design, read, and approved the final manuscript.
} 
una mayor intensidad de la $\mathrm{DCX}^{+}$y una menor de la GFAP+. No hubo modificación de los $\mathrm{NeuN}^{+}$, pero sí una reducción significativa de la $\mathrm{GFAP}^{+}$a los 30 días de la isquemia en los animales tratados comparados con los animales isquémicos no tratados.

Conclusión. La terapia con CDK5miR generó la recuperación neurológica de ratas isquémicas asociada con la inducción de la neurogénesis y el control de la capacidad de reacción de la proteína GFAP a corto y largo plazo después de la isquemia.

Palabras clave: isquemia encefálica; neurogénesis, cinasa 5 dependiente de la ciclina.

doi: https://doi.org/10.7705/biomedica.v38i4.3800

Cerebrovascular disease (CVD) represents a critical public health problem and it is considered the first cause of mental and physical disabilities around the world $(1,2)$. Ischemic stroke is a CVD, which mainly generates a focal ischemia by the occlusion of the middle cerebral artery characterized by a core and a penumbra zone (3). In the ischemic core, cellular necrotic events occur that make it impossible to rescue cells after the insult; however, the apoptotic cell death caused by nutrient deprivation, the oxidative stress, and the excitotoxicity occurring in the penumbra zone represent a key target for therapeutic intervention in cerebral ischemia $(4,5)$.

During cerebral infarction, various affected molecular actors are involved in neurotransmission, cell adhesion, and cytoskeletal remodelling, among others (6). CDK5 is a cyclin dependent kinase implied in neurodevelopment and neurotransmission, but its over-activation is associated with degeneration. Given that an increased cleavage of p35 (activator) to p25 generates an abnormal production of the CDK5/p25 complex with a sustained activation of the enzyme, an unbalancing phosphorylation of tau and of several substrates related to the loss of plasticity and neurovascular unit, as well as dementia (6-9), it has been suggested that the prevention of a sustained activity of CDK5 is neuroprotective (10-12).

In this context, it is necessary to gain a deeper understanding of CDK5 RNAi-based therapy for future translational studies in humans, which are in great clinical demand and have a significant social impact (13). In this study, we analyzed the role of CDK5miR on neurogenesis and gliogenesis after an ischemic stroke.

Corresponding author:

Gloria Patricia Cardona-Gómez, Sede de Investigación

Universitaria (SIU), Universidad de Antioquia, Calle $62 \mathrm{~N}^{\circ}$ 52-59, torre 1, piso 4, laboratorio 412, Medellín, Colombia

patricia.cardonag@udea.edu.co

Received: 24/02/17; accepted: 16/03/18

\section{Materials and methods}

\section{Animal model}

Procedures in animals were performed according to the ARRIVE guidelines, the "Guide for the care and use of laboratory animals", 8th edition, published by the National Institutes of Health (NIH), and the Colombian standards (Law 84/1989 and Resolution 8430/1993), taking special care to minimize suffering and reduce their number. The study was approved by the Ethics Committee for Animal Experimentation of the University of Antioquia, Medellín, Colombia.

Animals were obtained from a specific pathogen-free colony of the vivarium at the Sede de Investigación Universitaria (SIU), University of Antioquia, Medellín, Colombia. Rats were maintained in groups of five with food and water ad libitum and on a 12:12-hour dark:light cycle. We used 40 eight-week-old male Wistar rats (Rattus novergicus albinus) of average size and an average weight of $350 \mathrm{~g}$. Ten rats per experimental group were used for neurological scoring. In addition, we used 5 per experimental group for the histologic assessments.

\section{Surgical procedure}

We performed a transient middle cerebral artery occlusion (t-MCAO) and reperfusion as described previously $(12,14)$. Initially, animals were anaesthetized with a mixture of ketamine via IP $(60 \mathrm{mg} / \mathrm{kg}$; Holliday Scott S.A. Int. Neyer, Buenos Aires, Argentina), xylazine (5 mg/kg; Synthesis Ltda. \& Cia., S.C.A, Bogotá, Colombia), subcutaneous atropine $(100 \mathrm{mg} / \mathrm{kg}$; Erma S.A., Bogotá, Colombia); they also received an inhalational mixture of $2 \%$ to $4 \%$ of isoflurane (Baxter, Deerfield, IL, USA) and 96\% oxygen using an inhalation anaesthesia machine (VMC ${ }^{\mathrm{T}}$ Table top gas anaesthesia Instrument).

The right common carotid artery (CCA) was exposed and carefully isolated from the vagus nerve (VN); the right external and internal carotid arteries (ECA and ICA) were exposed and isolated. ECA ascending pharyngeal artery, superior thyroid and occipital 
branches were cauterized by electrocoagulation (AARON Bipolar Cautery ${ }^{\mathrm{TM}}$, Albany, NY, USA). The ICA artery pterygopalatine first branch was isolated. The distal portion of the ECA was tied with a 6/0 nylon and then cut. A 4-0 monofilament nylon (Corpaul, Bogotá, Colombia), previously rounded at one end by flaming and coated with poly-L-lysine solution $(0.1 \% \mathrm{w} / \mathrm{v}$ in deionized water; Sigma, St Louis, MO, USA), and inserted $17-19 \mathrm{~mm}$ from the ECA to the ICA to occlude the MCA and its origin. Then, we verified that the monofilament was not inside the pterygopalatine artery. The incision was sutured leaving a bulge of $1 \mathrm{~cm}$. After 60 minutes, the nylon was removed allowing reperfusion and the wound was closed.

Sham animals were subjected to the same procedures, but the filament was not introduced. Half of the animals were euthanized 15 days after reperfusion and the other half, 30 days after for which all animals were anesthetized with xylazine $10 \mathrm{mg} / \mathrm{kg}$ + ketamine $90 \mathrm{mg} / \mathrm{kg}$ and immediately perfused with $4 \%$ paraformaldehyde $(0.1 \mathrm{M}$ phosphate buffer [PBS], pH 7.4). Brains were carefully removed and post-fixed with $4 \%$ paraformaldehyde at $4^{\circ} \mathrm{C}$ for 48 hours, then preserved by a sucrose gradient
$(7 \%, 25 \%, 30 \%)$ at $4^{\circ} \mathrm{C}$; they were then placed in a cryopreservation solution at $-20^{\circ} \mathrm{C}$. Coronal sections were sectioned at $50 \mu \mathrm{m}$ with a vibrating blade microtome (VT1000S ${ }^{\mathrm{TM}}$, Leica Microsystems, Nussloch, Germany).

\section{Short hairpin RNAmiR delivery}

During the t-MCA occlusion, at 30 minutes, we performed a right hippocampal stereotaxic injection with anteroposterior (AP) coordinates of $-2.56 \mathrm{~mm}$, mediolateral (ML) $0.8 \mathrm{~mm}$ and dorsoventral (DV) 4.1 $\mathrm{mm}$. We used a $10 \mu \mathrm{L}$ Hamilton syringe for injection at a rate of $0.2 \mu \mathrm{L} / \mathrm{min}$ of a solution containing adeno-associated viral (AAV) particles obtained from the Davidson Laboratory (University of lowa Viral Vector Core) with the RNAi sequences for silencing CDK5 (short hairpin CDK5miR) and a control scrambled RNA sequence (shSCRmiR) $(12,15-18)$ for treating ischemic and control animals, respectively. Five minutes elapsed after the infusion before withdrawing the syringe. We injected a volume of $2.5 \mu \mathrm{l}$ of AAV2.5.shSCRmiR.GFP or AAV2.5.shCDK5miR.GFP as previously described $(12,18)$. After the injection, we proceeded to suture the animals keeping them in observation until their awakening (figure $1 \mathrm{~A}, \mathrm{~B}$ ).

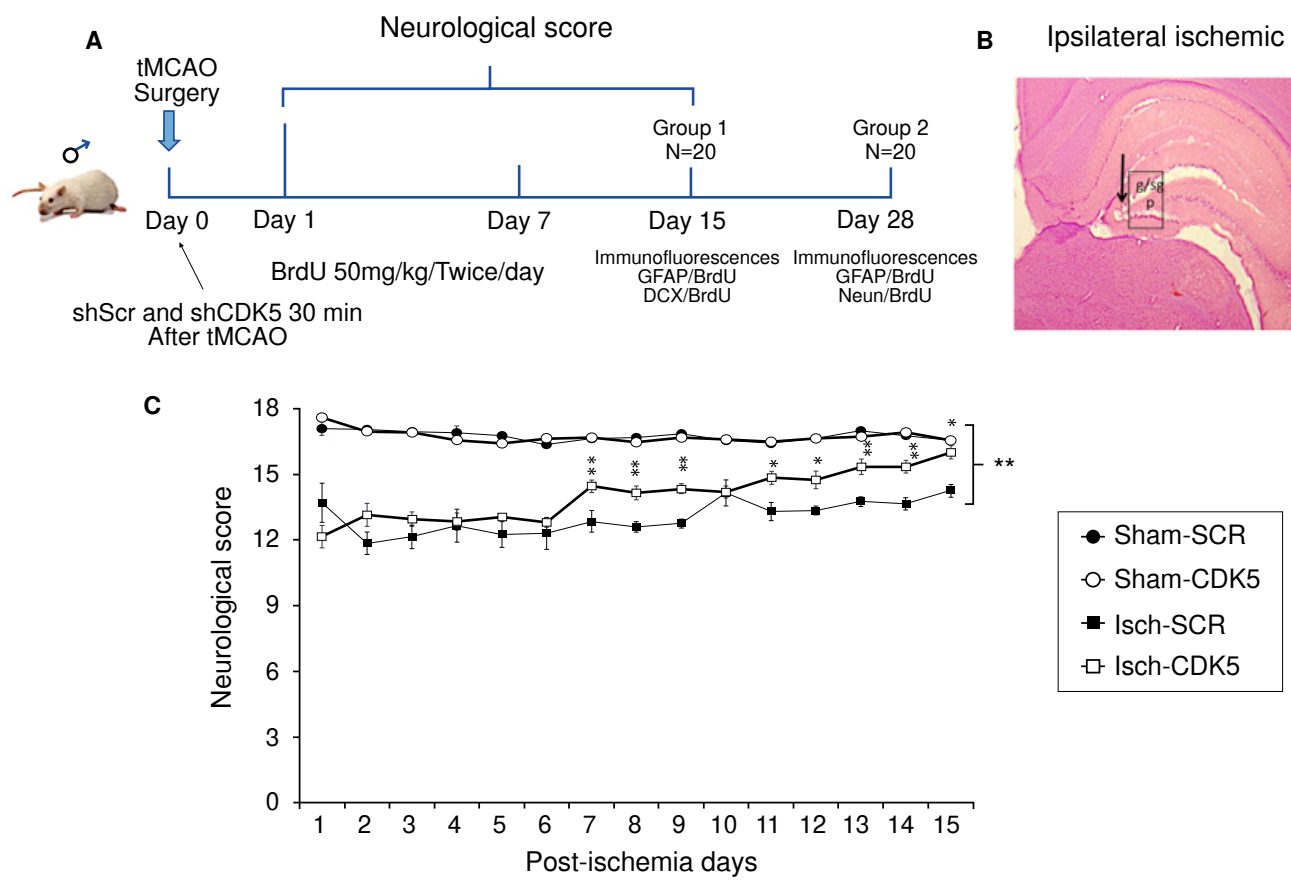

Figure 1. Neurological recovery induced by CDK5 silencing in ischemic rats. A) Experimental design to evaluate the effect of CDK5 RNAi on neural population and neurological performance after an ischemic insult. B) Ipsilateral injection site at stereotaxic coordinates AP -2.56, ML 0.8, and DV 4.1. and evaluated hippocampal regions (g: granular; sg: subgranular; p: polimorphic zone. C) Neurological analysis of CDK5 silencing in ischemic rats. The error bars indicate the SEM. All data are presented as mean \pm SEM. Sham-SCR: Control group treated with shSCRmiR; Sham-CDK5: Control group treated with shCDK5miR; Isch-SCR: Ischemic group treated with SCRmiR; Isch- CDK5: Ischemic group treated with shCDK5miR. $n=10, p<0.05={ }^{*} ; p<0.001={ }^{* *}$. 


\section{Recovery and neurological evaluation}

Animals were evaluated from day 1 to 15 after the t-MCAO $(\mathrm{N}=10)$. Neurological evaluation was scored on an 18-point scale. The evaluation was divided into six independent tests scored from 0 to 3 to determine the following parameters:

1) Cage exploration and spontaneous activity;

2) symmetry in limb movement;

3) forepaw outstretching;

4) climbing;

5) body proprioception, and

6 ) response to vibrissae touch $(12,18,19)$ (figure $1 \mathrm{~A}$ ).

The highest possible score in the tests was 18 , which indicated there were no neurological deficits, while the lowest was 3 for the most severe impairment. Neurological evaluation was performed every day and in the same order in all animals. To validate and reduce bias, a double-blind procedure was performed recording videos for every animal during the test.

\section{Insertion of 5-Bromo-2-deuxyuridine}

For the BrdU (Catalog Number B5002, SigmaAldrich) insertion, we injected rats via IP twice a day during seven days after ischemia at $50 \mathrm{mg} / \mathrm{kg}$ (0.1 M phosphate buffer [PBS], $\mathrm{pH} 7.4$ ).

\section{Immunohistochemistry}

Brain sections were treated with methanol and hydrogen peroxide $\left(\mathrm{H}_{2} \mathrm{O}_{2}\right)$ in $0.1 \mathrm{M}$ PBS $(\mathrm{pH} 7.4)$ to inhibit endogenous peroxidase activity for 20 minutes while free-floating with moderate shaking. Subsequently, we washed them three times with $0.3 \%(\mathrm{v} / \mathrm{v})$ Triton X-100 $\mathrm{TM}$ (Sigma-Aldrich) in 0.1 $M$ PBS to increase tissue permeability and we then incubated for 30 minutes with Triton ${ }^{\mathrm{TM}} 0.5 \%$ $(\mathrm{v} / \mathrm{v}) \mathrm{X}-100$ in $0.1 \mathrm{M}$ PBS. Then, we backwashed with $0.3 \%(\mathrm{v} / \mathrm{v})$ Triton $\mathrm{X}-100^{\mathrm{TM}}$ in $0.1 \mathrm{M}$ PBS for three times.

For BrdU, we denaturalized brain DNA sections with $\mathrm{HCl} 2 \mathrm{~N}$ for 20 minutes at $37^{\circ} \mathrm{C}$, we washed three times with $0.3 \%(\mathrm{v} / \mathrm{v})$ Triton $\mathrm{X}-100^{\mathrm{TM}}$ in $0.1 \mathrm{M}$ PBS, then incubated with citrate buffer (Sodium citrate $10 \mathrm{Mm}, 0.05 \%$ tween $20, \mathrm{pH} 6.0$ ) for 10 minutes at room temperature and, finally, we washed three times with $0.3 \%(\mathrm{v} / \mathrm{v})$ TritonX-100 10 in $0.1 \mathrm{M}$ PBS. Nonspecific binding sites were blocked by preincubation with BSA (1\%) and $0.3 \%(\mathrm{v} / \mathrm{v})$ Triton $\mathrm{X}-100^{\mathrm{TM}}$ in $0.1 \mathrm{M}$ PBS for 1 hour.
Sections were incubated 24 hours while freefloating with moderate shaking and with the primary anti-body diluted in incubation solution $(0.1 \mathrm{M}$ PBS with $0.3 \%(\mathrm{v} / \mathrm{v})$ Triton $\mathrm{X}-100^{\mathrm{TM}}$ and $\left.0.3 \% \mathrm{BSA}\right)$ at $4^{\circ} \mathrm{C}$.

Anti-BrdU (1:100 mouse monoclonal B8434, SigmaAldrich) was used to detect bromodeoxyuridine (BrdU) specifically incorporated into the DNA. Next day, sections were washed 5 minutes with $0.1 \mathrm{M}$ PBS three times and incubated with the secondary antibody (1:250 biotinylated mouse, Pierce) for 1 hour at room temperature and then washed 3 times with $0.1 \mathrm{M}$ PBS, incubated with Avidin-Biotin complex (Pierce complex ${ }^{\mathrm{TM}}$; 1: 250 reagents $A$ and $B$ ), and washed again three more times and developed with a chromogenic reaction diaminobenzidine (DBA) in $0.01 \% \mathrm{H}_{2} \mathrm{O}_{2}$. For negative controls, we followed the same protocol for each experimental group without incubation with the respective primary antibody.

Sections were mounted on glass slides, dehydrated with increasing concentration of alcohol $70 \%, 96 \%$, $100 \%)$ and cleared with xylene. Finally, the slides were sealed using Vecta-shield mounting medium (Vector Laboratories, Burlingame, CA, USA), and then analyzed through a light microscope (Nikon Eclipse E200'TM). Images were captured using a Nikon digital camera (Sight DS-L1 ${ }^{\mathrm{TM}}$ ). Quantification of immunoreactivity in the hippocampus was determined using a 10X objective. Photomicrographs were analyzed using the ImageJ software program (version 1.45, US National Institutes of Health, Bethesda, MD, USA). To quantify the relative intensity of immunostaining, we modified the images to a binary system and obtained integrated densities (relative units) substracting automatically the background for each image.

\section{Immunofluorescence}

Brain slices were initially heated $\left(80^{\circ} \mathrm{C}\right)$ in $10 \mathrm{mM}$ Tris $\mathrm{pH} 6.0$ to increase exposure of the antigen and then treated with ammonium chloride $\left(\mathrm{NH}_{4} \mathrm{Cl}\right)$ for 20 minutes to avoid autofluorescence. Three washes with $0.3 \% \mathrm{v} / \mathrm{v}$ Triton $\mathrm{X}-100^{\mathrm{TM}}$ in $0.1 \mathrm{M}$ PBS were made to increase tissue permeability. For BrdU, we denaturalized DNA brain sections with $\mathrm{HCl} 2 \mathrm{~N}$ for 20 minutes at $37^{\circ} \mathrm{C}$, washed them three times with $0.3 \%(\mathrm{v} / \mathrm{v})$ Triton $\mathrm{X}-100^{\mathrm{TM}}$ in $0.1 \mathrm{M}$ PBS, and then incubated them with citrate buffer (sodium citrate $10 \mathrm{Mm}, 0.05 \%$ tween 20, pH 6.0) for 10 minutes at room temperature to finally wash them three times with $0.3 \%(\mathrm{v} / \mathrm{v})$ Triton $\mathrm{X}-100^{\mathrm{TM}}$ in 
$0.1 \mathrm{M}$ PBS. Nonspecific binding sites were blocked by preincubation with BSA (3\%) and $0.5 \%(\mathrm{v} / \mathrm{v})$ Triton X-100 ${ }^{\mathrm{TM}}$ in $0.1 \mathrm{M}$ PBS for 1 hour.

Sections were incubated overnight while freefloating with moderate shaking at $4^{\circ} \mathrm{C}$ with the respective primary anti-BrdU (mouse monoclonal 1: 100, Sigma) for the new cells produced, antiDCX (polyclonal rabbit 1: 250, Abcam) for immature neurons, anti-GFAP (rabbit polyclonal 1: 500, Sigma) for astrocytic cells and anti-NeuN (polyclonal rabbit 1: 500, Millipore) for mature neuronal cells. After three washes, tissues were incubated with secondary antibodies: Rabbit Alexa Fluor $594^{\mathrm{TM}}$, and mouse Alexa Fluor $350^{\mathrm{TM}}$ (molecular probes, $1: 1,000)$ for 90 minutes at room temperature. Finally, we washed with PBS and slides were coverslipped using Gel Mount ${ }^{\mathrm{TM}}$ (BioMeda, Hatfield, PA, USA) in dark conditions. For negative controls, we followed the same protocol for each experimental group without incubation with the respective primary antibodies. Tissues were observed with a motorized spinning disk confocal microscope (Disk Scan Unit) Olympus IX 81 ${ }^{\mathrm{TM}}$ (Olympus, Latin America, Inc., Miami, FL, USA). Images were photographed at $10 \mathrm{X}$ and the analysis was performed by evaluating the fluorescence intensity (FI) using the Image Pro Plus (Media Cybernetics) software.

\section{Statistical analysis}

For the neurological analysis, we used ten (10) animals per group and for the histological analysis, five (5) per group. The data obtained from the neurological and tissue immunoreactivity evaluations were analyzed using a homogeneity of variance test, followed by ANOVA of repeated measurement and one-way ANOVA tests, and a Tukey's post hoc test to define differ-ences between groups. We used the SPSS Statistics ${ }^{\mathrm{TM}}$ software (20.0 version) and a $p \leq 0.05$ significance. All experimental groups were processed in parallel for reducing variability. The data are presented as mean \pm SEM.

\section{Results}

\section{CDK5 reduction promoted neurological recovery in ischemic rats}

The neurological assessment showed that the Isch-SCR animals had a lower score (12.8 and 14.3 points) at days 7 and 15 post-ischemia, respectively, compared with the sham groups with and without CDK5 RNAi treatment (16.5 points). Interestingly, the CDK5 RNAi-treated ischemic group presented a significantly higher score of 14.5 on day 7 and of 16 points on day 15, recovering neurological skills similar to those of the control animals (figure 1C; $p<0.05={ }^{*}, p<0.001={ }^{* *}$, repeated-measures in ANOVA).

\section{BrdU incorporation in the hippocampus was promoted by CDK5 RNAi treatment in ischemic rats}

We found a significantly increased number of $\mathrm{BrdU}^{+}$cells in the Isch-SCR group compared with the sham-SCR and sham-CDK5 controls (figure $2 \mathrm{~A}$ a; $p<0.05={ }^{*}, p<0.001={ }^{* *}$, repeatedmeasures in ANOVA and Tukey's test). However, the CDK5 RNAi treatment induced a significantly greater incorporation of $\mathrm{BrdU}$ in ischemic animals compared with the Isch-SCR group without treatment (figure $2 \mathrm{~A}$ a). Although there was no significant incorporation of BrdU in the polymorphic area of the Isch-SCR animals compared to controls (figure 2A b; $p<0.05={ }^{*}, p<0.001={ }^{* *}$, repeated-measures in ANOVA and Tukey's test), CDK5 silencing significantly increased $\mathrm{BrdU}^{+}$cells compared to Isch-SCR and controls in the cerebral zone (figure 2A b). This effect of CDK5 RNAi on ischemic rats remained for a month in the granular/ subgranular and polymorphic zones (figure $2 \mathrm{~B} \mathrm{~b}$ ). The Isch-group had a slight tendency or significantly increased $\mathrm{BrdU}^{+}$cells in comparison with the control groups (figure $2 \mathrm{~B} \mathrm{a}, \mathrm{b}$ ).

\section{CDK5 RNAi exerted neuroprotection associated with the induction of immature neurons and down-regulation of the astroglial population in ischemic rats}

Our findings showed that CDK5 RNAi treatment induced proliferation of immature neurons in the granular/subgranular zones. This is supported by the significant increase of $\mathrm{BrdU}^{+}$and $\mathrm{DCX}^{+}$cells in comparison with ischemic and control groups at 15 days post-ischemia (figure $3 \mathrm{~A}, \mathrm{C}$; $\mathrm{p}<0.05={ }^{*}$, $p<0.001={ }^{* *}$, repeated-measures in ANOVA and Tukey's test). Although the sham-CDK5 and IschSCR groups presented a significant increase of $\mathrm{BrdU}$ in the granular/subgranular zones, this was not confirmed by the variations in the amount of $\mathrm{DCX}^{+}$or $\mathrm{GFAP}^{+}$cells (figure $3 \mathrm{~A}, \mathrm{C}$ ). On the other side, the polymorphic zone presented variability between groups and treatments (figure 3B, c; $p$ $<0.05={ }^{*}, p<0.001={ }^{* *}$, repeated-measures in ANOVA and Tukey's test), however, there was a significant increase of $\mathrm{BrdU}^{+}$and $\mathrm{GFAP}^{+}$cells in the ischemic-SCR group 15 days post-ischemia, which was significantly down-regulated by the CDK5 RNAi treatment in ischemic rats (figure 3B, C). The green fluorescent protein (GFP) was used 


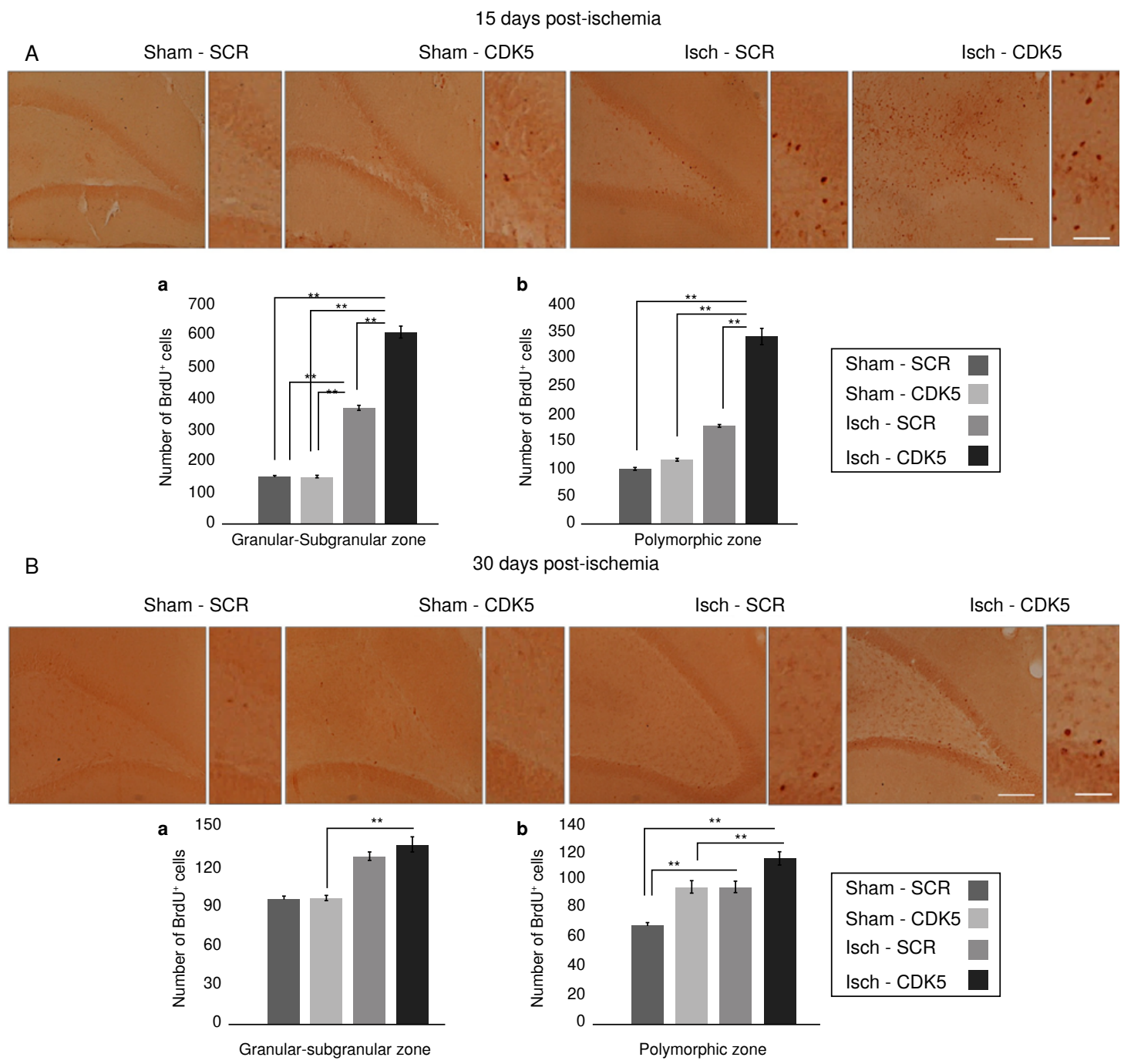

Figure 2. BrdU incorporation in the hippocampus of CDK5 RNAi-treated ischemic rats. A) Representative images at bregma -2.56 $\mathrm{mm}$ of BrdU immunoreactivity in the granular-subgranular (a) and polymorphic (b) zones at 15 days and B) 28 days post-ischemia in treated and untreated rats. The error bars indicate the SEM. $n=5, p<0.05={ }^{*} ; p<0.001={ }^{* \star}$. All data are presented as mean \pm SEM. 10X. Scale bar $=100 \mu \mathrm{m}$.

to confirm the expression of AAV2.5.shSCRmiR. GFP and AAV2.5.shCDK5miR.GFP in each group, respectively.

\section{CDK5 RNAi preserved the down-regulation of astrogliosis at one month post-ischemia}

Interestingly, when we evaluated the neural population at 30 days post-ischemia, we did not find changes in the mature neuron immunoreactivity neither in the granular/subgranular nor in the polymorphic zones in the untreated and treated rats, because there was a significant increase in the $\mathrm{BrdU}^{+}$cells but without changes in the NeuN immunoreactivity (figure 4A, B; $p<0.05=$ ${ }^{*}, p<0.001={ }^{* *}$, repeated measures in ANOVA and Tukey's test). The GFAP ${ }^{+}$population did not present changes in the granular/subgranular zone either (figure 4A, B), but stayed increased in the polymorphic zone at one-month post-ischemia in untreated rats, which was reversed by the CDK5 RNAi treatment as in the control groups (figure 4A, C, $p<0.05={ }^{*}, p<0.001={ }^{*}$, repeated measures in ANOVA and Tukey's test).

\section{Discussion}

Our data suggest that CDK5 RNAi exerts part of its neuroprotection effect by controlling immature neuron proliferation and reducing astroglial cells, which reflects in the recovery of the neurological function after an ischemic stroke. 


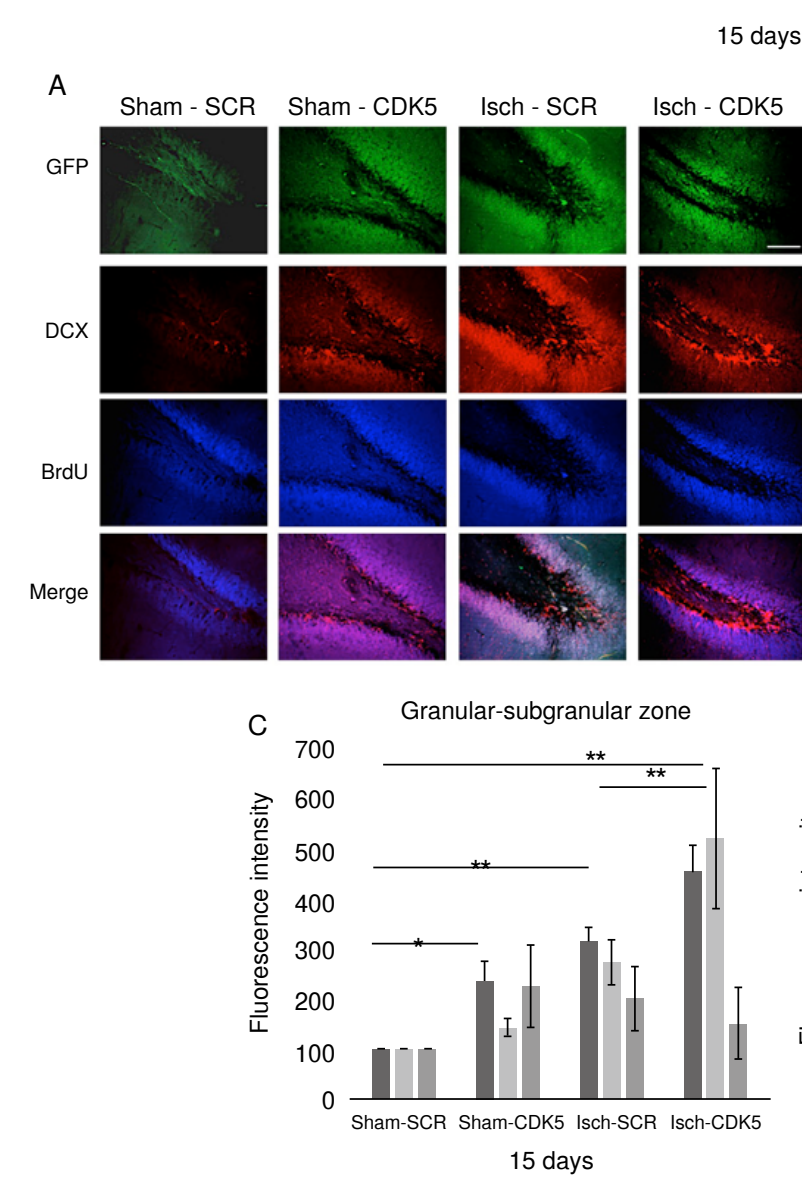

5 days post-ischemia
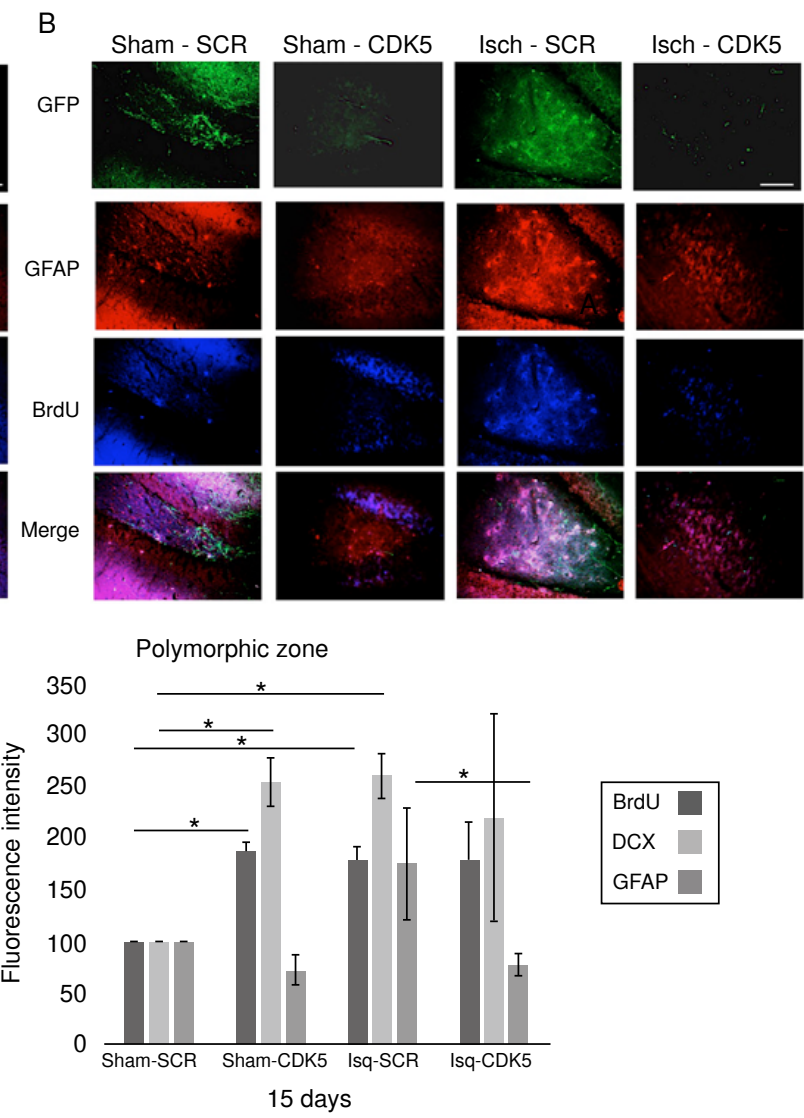

Figure 3. CDK5 RNAi induced immature neurons and down-regulation of astroglial population in ischemic rats. A) BrdU and DCX immunoreactivities in the granular-subgranular and polymorphic zones at 15 days post-ischemia in treated and untreated rats (A, C). $\mathrm{BrdU}$ and GFAP in the granular-subgranular and polymorphic zones $(B, C)$ at 15 days post-ischemia in treated and untreated rats. The error bars indicate the SEM. $n=5, p<0.05={ }^{*} ; p<0.001={ }^{* *}$. All data are presented as mean \pm SEM. Representative images at bregma $-2.56 \mathrm{~mm}$. 10X. Scale bar $=100 \mu \mathrm{m}$.

CDK5 is an effective form of protection against an ischemic event (7), preventing the excitotoxic spreading of glutamate by the reduction of calpain and CDK5 activation $(12,20)$.

Complementarily, the present study suggests that the silencing of CDK5 in the hippocampus has positive consequences on the behaviour associated with the motor cortex (M1 and M2) and the sensory area (S1) (21-24) as the exploratory behaviour integrate the interaction of those areas in the spatial activity performed by the hippocampus (2426), whisker movement through the motor cortex by M1 stimulation, which strongly innervates reticular nuclei containing cholinergic premotor neurons of the vibrissae and, in parallel, the sensory cortex S1, which innervates the trigeminal interpolar nuclei of brainstem and plays a role in the retraction of the whiskers and, in turn, in the sensitivity of the paretic side of the animals $(25,26)$.
In addition, our recent observations support the influence of hippocampal CDK5 down-regulation on the neurological tasks and the performance of learning and memory functions, where the CDK5 RNAi avoids cell death on cingulate cortex and thalamus at one and four months post-ischemia (unpublished data); these cerebral areas are involved in motivation and motor control behaviours $(27,28)$. Its mode of action also involves the BDNF/ TRKB pathway and the restoration of long-term potentiation (LTP) dysfunction after stroke in the hippocampus at one-month post-ischemia $(12,18)$.

On the other hand, BrdU has been widely used for labelling new-born cells and proliferation of different cell types. It has been shown that in cerebral ischemia the inclusion of BrdU is a marker of proliferation or neurogenesis in brain niches (29), which was confirmed in our observations. It is well known that CDK5 plays an important role in 
A
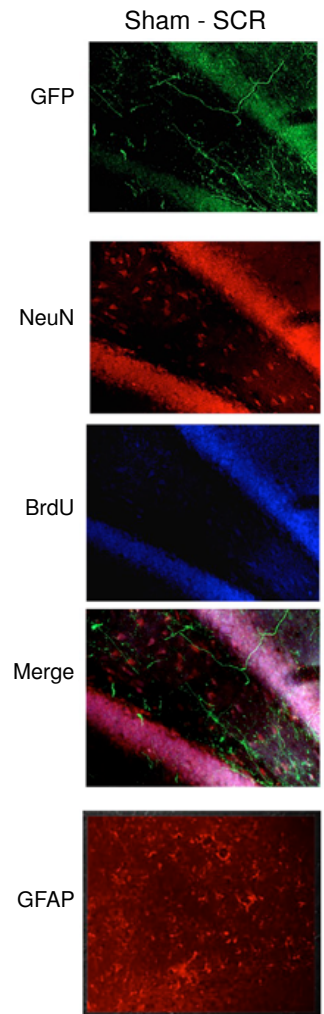

30 days post-ischemia
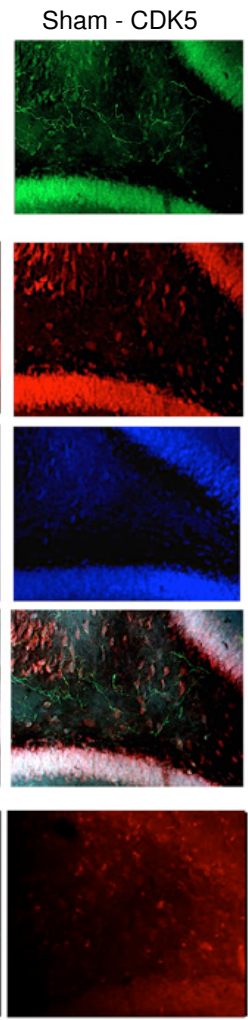
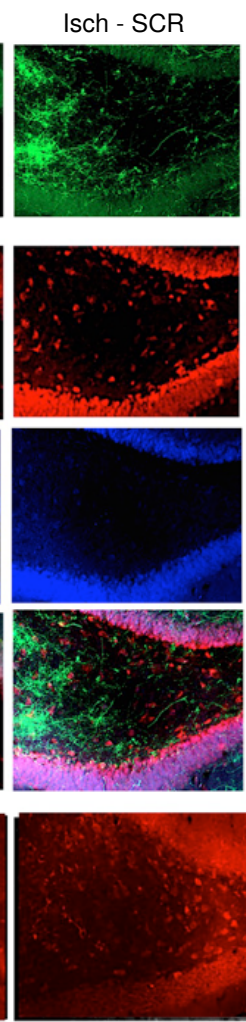
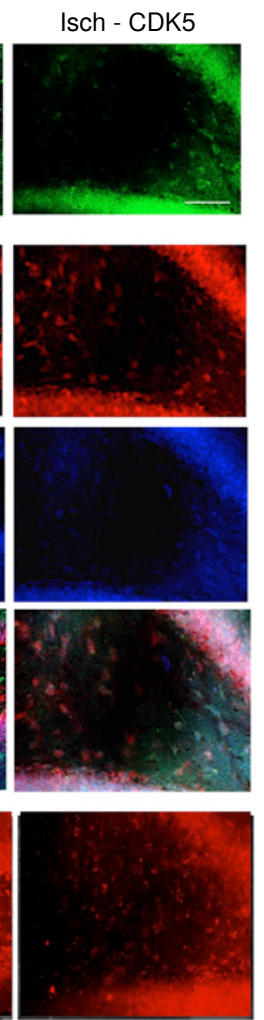

B

Granular-subgranular zone
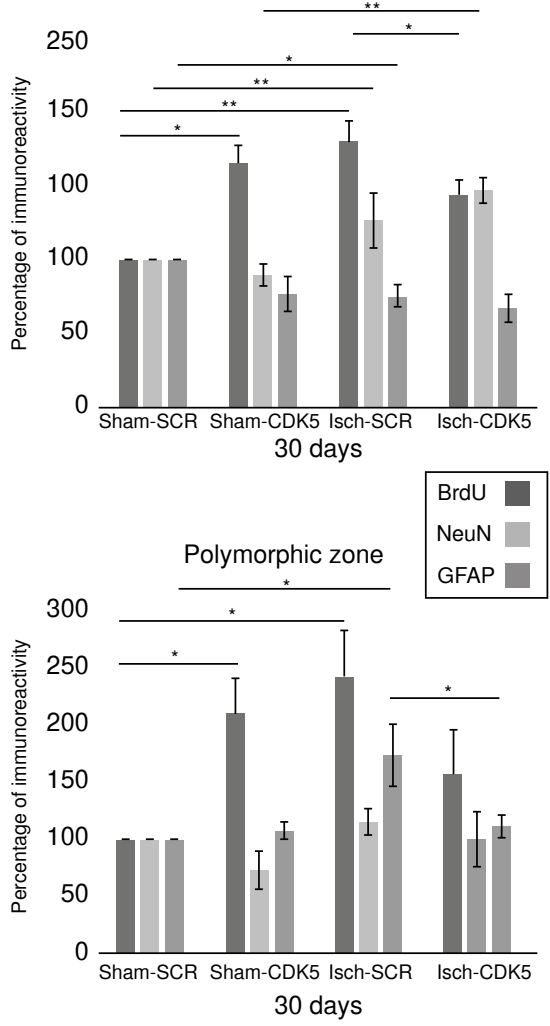

Figure 4. CDK5 RNAi prevents astrogliosis at one-month post-ischemia. A) NeuN, BrdU and GFAP immunoreactivities in the granular-subgranular (A, B) and polymorphic $(\mathrm{A}, \mathrm{C})$ zones at 30 days post-ischemia in treated and untreated rats. The error bars indicate the SEM. All data are presented as mean+/-SEM. Representative images at bregma $-2.56 \mathrm{~mm} . n=5, p<0.05={ }^{*} ; p<0.001=$ ${ }^{* *}$. 10X. Scale bar $=100 \mu \mathrm{m}$

post-mitotic neurons, where its inhibition prevents immature neuron migration and progression to a mature stage in physiological conditions (30). But the cellular and molecular fate depend on the contexts and homeostatic balance between normal and pathological conditions $(12,18)$.

In our findings, CDK5 silencing in ischemia increased the BrdU/DCX ${ }^{+}$cells, maybe because its reduction could regulate the re-entry in the cell cycle for a correct balance between Cdk6 and Cdk4 and the E2F1/CDK5 nuclear complex (31$36)$, or by the prevention of stem cell differentiation as CDK5 activity promotes neural differentiation through phosphorylation of the p27 protein in its 187-threonine residue (37). Moreover, CDK5 may phosphorylate to DCX, an immature neurons marker, in the 297-serine residue during migration (38). Therefore, our data would suggest that CDK5 RNAi induces DCX in an early stage, but it does not facilitate its migration and maturation since NeuN labelling was unmodified.
It has also been described that CDK5 RNAi induces the production of BDNF $(14,18)$, a neurotrophic factor highly involved in neurogenesis, neuronal plasticity, and protection preventing proinflammatory response $(39,40)$. The neuroprotective action of CDK5 RNAi increased activation of a typical plasticity pathway, the BDNF/ERK/CREB, and its action is dependent on the TRKB receptor activity $(18,39,40,41)$. Also, ERK signalling has been widely described as a mediator of neuronal plasticity and survival in physiological and neurodegenerative contexts (41).

Those sequential cascades of CDK5 RNAi-induced survival and plasticity events could also be associated with the control of astrocytes reactivity. GFAP is a marker of astrogliosis on brain disease, and its proliferation is related to the adverse progression of brain impairment, pro-inflammatory response, lymphocytic infiltration, cytokines release, and neurovascular uncoupling $(1,3,6)$. Interestingly, CDK5 knock-down could prevent the astrogliosis 
in the short and long time post-injury, thus supporting the potential translation of CDK5 RNAibased therapy $(7,12,18,42,43)$.

On the other hand, when CDK5 levels are decreased in astroglial cells, BDNF is released from those cells protecting neurons (42) and endothelial cells in co-cultures (unpublished data), and recovering motor and neurological functions in ischemic rats (43).

Moreover, our data suggest that CDK5 RNAi induces proliferation of other types of cells besides neurons, which were not detected by our current approach. However, in agreement with our previous studies we have found that silencing of CDK5 induces an increase of endothelial cell marker PECAM1(43) and the adhesion cell protein p120ctn in the membrane of endothelial cells (unpublished data), suggesting that endothelial cells may be the other potential cell population involved in the CDK5 RNAi-induced neuroprotection. This is supported by the recovery of the neurovascular unit as we have suggested previously (6), and is reflected in the physiological recovery of the neurological performance $(14,18,42,43)$.

In conclusion, our data suggest CDK5 reduction induces proliferation of immature neurons and blocks astrogliosis in the long-term after ischemic injury improving neurological function, which, together with previous scientific evidence, supports the potential translation of CDK5 RNAi-based gene therapy in acute and chronic neurodegeneration.

\section{Acknowledgments}

We would like to thank Dr. Angel Céspedes-Rubio at the Universidad de Tolima, Colombia, and Jean Paul Delgado Charris, at Universidad de Antioquia, Colombia, for their recommendations during the development of this research. We also thank the support we received during our experiments from the Grupo de Neurociencias de Antioquia, Área de Neurobiología Celular y Molecular, Facultad de Medicina, Universidad de Antioquia.

\section{Conflicts of interest}

The authors certify there is no conflict of interests regarding the institutions that financed and support this project.

\section{Funding}

This research was funded by Colciencias (project 111554531400).

\section{References}

1. Lo EH, Dalkara T, Moskowitz MA. Mechanisms, challenges and opportunities in stroke. Nat Rev Neurosci. 2003;4:399415. https://doi.org/10.1038/nrn1106

2. Lo EH. Experimental models, neurovascular mechanisms and translational issues in stroke research. $\mathrm{Br} \mathrm{J}$ Pharmacol. 2003;153(Suppl.1):S396-405. https://doi.org/10.1038/sj.bjp. 0707626

3. Murphy TH, Corbett C. Plasticity during stroke recovery: From synapse to behavior. Nat Rev Neurosci. 2009;10:86172. https://doi.org/10.1038/nrn2735

4. Mehta SL, Manhas N, Raghubir R. Molecular targets in cerebral ischemia for developing novel therapeutics. Brain Res Rev. 2007;54:34-66. https://doi.org/10.1016/j. brainresrev.2006.11.003

5. Baron JC, von Kummer R, del Zoppo GJ. Treatment of acute ischemic stroke. Challenging the concept of a rigid and universal time window. Stroke. 1995;26:2219-21.https:// doi.org/10.1161/01.STR.26.12.2219

6. Posada-Duque RA, Barreto GE, Cardona-Gómez GP. Protection after stroke: Cellular effectors of neurovascular unit integrity. Front Cell Neurosci. 2014;8:231. https://doi. org/10.3389/fncel.2014.00231

7. Meyer DA, Torres-Altoro MI, Tan Z, Tozzi A, Di Filippo M, DiNapoli V, et al. Ischemic stroke injury is mediated by aberrant Cdk5. J Neurosci. 2014;34,8259-67. https://doi. org/10.1523/JNEUROSCI.4368-13.2014

8. Chang KH, de Pablo Y, Lee HP, Lee HG, Smith MA, Shah K. Cdk5 is a major regulator of p38 cascade: Relevance to neurotoxicity in Alzheimer's disease. J Neurochem. 2010; 113:1221-9. https://doi.org/10.1111/j.1471-4159.2010.06687.x

9. Lopes JP, Agostinho P. Cdk5: Multitasking between physiological and pathological conditions. Prog Neurobiol. 2011; 94:49-63. https://doi.org/10.1016/j.pneurobio.2011. 03.006

10. Chang KH, Vincent F, Shah K. Deregulated Cdk5 triggers aberrant activation of cell cycle kinases and phosphatases inducing neuronal death. J Cell Sci. 2012;125:5124-37. https://doi.org/ 10.1242/jcs.108183

11. Meyer DA, Torres-Altoro MI, Tan Z, Tozzi A, Di Filippo M, DiNapoli V, et al. Ischemic stroke injury is mediated by aberrant Cdk5. J Neurosci. 2014;34:8259-67. https://doi. org/ 10.1523/JNEUROSCI.4368-13.2014

12. Gutiérrez-Vargas JA, Múnera A, Cardona-Gómez GP. CDK5 knockdown prevents hippocampal degeneration and cognitive dysfunction produced by cerebral ischemia. J Cereb Blood Flow Metab. 2015;35:1937-49. https://doi. org/10.1038/jcbfm.2015.150

13. Khaja AM, Grotta JC. Established treatments for acute ischemic stroke. Lancet. 2007;369:319-30. https://doi. org/10.1016/S0140-6736(07)60154-8

14. Gutiérrez-Vargas JA, Muñoz-Manco Jl, García-Segura LM, Cardona-Gómez GP. GluN2B N-Methyl-D-aspartic acid receptor subunit mediates atorvastatin-induced neuroprotection after focal cerebral ischemia. J Neurosci Res. 2014;92:1529-48. https://doi.org/10.1002/jnr.23426 
15. Piedrahita D, Hernández I, López-Tobón A, Fedorov D, Obara B, Manjunath BS, et al. Silencing of CDK5 reduces neurofibrillary tangles in transgenic Alzheimer's mice. J Neurosci. 2010;30:13966-76. https://doi.org/10.1523/ JNEUROSCI.3637-10.2010

16. Posada-Duque RA, López-Tobón A, Piedrahita D, González-Billault C, Cardona-Gómez GP. p35 and Rac1 underlie the neuroprotection and cognitive improvement induced by CDK5 silencing. J Neurochem.2015;134:354-70 https://doi.org/10.1111/jnc.13127

17. Posada-Duque RA, Palacio-Castañeda V, CardonaGómez GP. CDK5 knockdown in astrocytes provide neuroprotection as a trophic source via Rac1. Mol Cell Neurosci. 2015;68:151-66. https://doi.org/10.1016/j.mcn.2015.07.001

18. Gutiérrez-Vargas JA, Moreno H, Cardona-Gómez GP. Targeting CDK5 post-stroke provides long-term neuroprotection and rescues synaptic plasticity. J Cereb Blood Flow Metab. 2016;37:2208-23. https://doi.org/0271678X16662476

19. García JH, Wagner S, Liu KF, Hu XJ. Neurological deficit and extent of neuronal necrosis attributable to middle cerebral artery occlusion in rats. Statistical validation. Stroke. 1995;26:627-35. https://doi.org/10.1161/01.STR.26.4.627

20. Chang KH, Multani PS, Sun KH, Vincent F, de Pablo $\mathbf{Y}$, Ghosh S, et al. Nuclear envelope dispersion triggered by deregulated Cdk5 precedes neuronal death. Mol Biol Cell. 2011;22:1452-62. https://doi.org/10.1091/mbc.E10-07-0654

21. Schmidt-Kastner R, Freund TF. Selective vulnerability of the hippocampus in brain ischemia. Neuroscience. 1991;40: 599-636. https://doi.org/10.1016/0306-4522(91)90001-5

22. Jin K, Sun Y, Xie L, Peel A, Ou-Mao X, Batteur S, et al. Directed migration of neuronal precursors into the ischemic cerebral cortex and striatum. Mol Cell Neurosci. 2003;24: 171-89. https://doi.org/10.1016/S1044-7431(03)00159-3

23. Andersen P, Morris R, Amaral D, Bliss T, O'Keefe J. The Hippocampus Book. First edition. Oxford Neuroscience Series. Oxford: Oxford University Press, Inc.; 2007. p. 872.

24. Harrison TC, Silasi G, Boyd JD, Murphy TH. Displacement of sensory maps and disorganization of motor cortex after targeted stroke in mice. Stroke. 2013;44:2300-6. https://doi. org/10.1161/STROKEAHA.113.001272

25. Preston AR, Eichenbaum H. Interplay of hippocampus and prefrontal cortex in memory. Curr Biol. 2013;23:R764-73. https://doi.org/10.1016/j.cub.2013.05.041

26. Petersen CC. Cortical control of whisker movement. Annu Rev Neurosci. 2014;37:183-203. https://doi.org/10.1146/ annurev-neuro-062012-170344

27. Paus P. Primate anterior cingulate cortex: Where motor control, drive and cognition interface. Nat Rev Neurosci. 2001;2:417-24. https://doi.org/10.1038/35077500

28. Sherman SM. Thalamus plays a central role in ongoing cortical functioning. Nat Neurosci. 2016;16:533-41. https:// doi.org/10.1038/nn.4269

29. Taupin P. BrdU immunohistochemistry for studying adult neurogenesis: Paradigms, pitfalls, limitations, and validation. Brain Res Rev. 2007;53:198-214. https://doi. org/10.1016/j.brainresrev.2006.08.002
30. Legace DC, Benavides DR, Kansy JW, Mapelli M, Greengard P, Bibb JA, et al. Cdk5 is essential for adult hippocampal neurogenesis. Proc Natl Acad Sci USA. 2008; 105:18567-71. https://doi.org/10.1073/pnas.0810137105

31. Zhang J, Li H, Yabut O, Fitzpatrick H, D'Arcangelo G, Herrup K. Cdk5 suppresses the neuronal cell cycle by disrupting the E2F1-DP1 complex. J Neurosci. 2010;30:521928. https://doi.org/10.1523/JNEUROSCI.5628-09.2010

32. Maestre C, Delgado-Esteban M, Gómez-Sánchez JC, Bolaños JP, Almeida A. Cdk5 phosphorylates Cdh1 and modulates cyclin B1 stability in excitotoxicity. EMBO J. 2008;27:2736-45. https://doi.org/10.1038/emboj.2008.195

33. Artegiani B, Lindemann D, Calegari F. Overexpression of Cdk4 and cyclin D1 triggers greater expansion of neural stem cells in the adult mouse brain. J Exp Med. 2011;208: 937-48. https://doi.org/10.1084/jem.20102167

34. Beukelaers P, Vandenbosch R, Caron N, Nguyen L, Belachew S, Moonen G, et al. Cdk6-dependent regulation of $G(1)$ length controls adult neurogenesis. Stem Cells. 2011;29:713-24. https://doi.org/10.1002/stem.616

35. Veas-Pérez de Tudela M, Maestre C, Delgado-Esteban M, Bolaños JP, Almeida A. Cdk5-mediated inhibition of APC/C-Cdh1 switches on the cyclin D1-Cdk4-pRb pathway causing aberrant S-phase entry of postmitotic neurons. Sci Rep. 2015;5:18180. https://doi.org/10.1038/srep18180

36. Niu Y, Li H, Herrup K, Zhang J. Neuronal cell cycle regulation of Cdk5 in Alzheimer's disease. Brain Disord Ther. 2012;S1:004. https://doi.org/10.4172/2168-975X.S1-004

37. Zheng YL, Li BS, Rudrabhatla P, Shukla V, Amin ND, Maric D, et al. Phosphorylation of p27Kip1 at Thr187 by cyclin-dependent kinase 5 modulates neural stem cell differentiation. Mol Biol Cell. 2010;21:3601-14. https://doi. org $/ 10.1091 / \mathrm{mbc} . E 10-01-0054$

38. Tanaka T, Serneo FF, Tseng HC, Kulkarni AB, Tsai LH, Gleeson JG. Cdk5 phosphorylation of doublecortin ser297 regulates its effect on neuronal migration. Neuron. 2004; 41:215-27. https://doi.org/10.1016/S0896-6273(03)00852-3

39. Park H, Poo MM. Neurotrophin regulation of neural circuit development and function. Nat Rev Neurosci. 2013;14:723. https://doi.org/10.1038/nrn3379

40. Lu B, Nagappan G, Guan X, Pradeep JN, Wren P. BDNFbased synaptic repair as a disease-modifying strategy for neurodegenerative diseases. Nat Rev Neurosci. 2013;14: 401-16. https://doi.org/10.1038/nrn3505

41. Fournier NM, Lee B, Banasr M, Elsayed M, Duman RS. Vascular endothelial growth factor regulates adult hippocampal cell proliferation through MEK/ERK- and PI3K/Aktdependent signaling. Neuropharmacology. 2012;63:642-52. https://doi.org/10.1016/j.neuropharm.2012.04.033

42. Posada-Duque RA, Ramírez O, Härtel S, Inestrosa NC, Bodaleo F, González-Billault C, et al. CDK5 downregulation enhances synaptic plasticity. Cell Mol Life Sci. 2017;74:153. https://doi.org/10.1007/s00018-016-2333-8

43. Becerra-Calixto A, Cardona-Gómez GP. Neuroprotection induced by transplanted CDK5 knockdown astrocytes in global cerebral ischemic rats. Mol Neurobiol. 2017;54: 6681-96. https://doi.org/10.1007/s12035-016-0162-2 